\title{
Prevalence of and risk factors for persistent postoperative nonanginal pain after cardiac surgery: a 2-year prospective multicentre study
}

\author{
Manon Choinière PhD, Judy Watt-Watson PhD, J. Charles Victor PhD, Roger J.F. Baskett MD, \\ Jean S. Bussières MD, Michel Carrier MD, Jennifer Cogan MD MSc, Judy Costello MSc, \\ Christopher Feindel MD, Marie-Claude Guertin PhD, Mélanie Racine PhD, Marie-Christine Taillefer PhD
}

\begin{abstract}
Background: Persistent postoperative pain continues to be an underrecognized complication. We examined the prevalence of and risk factors for this type of pain after cardiac surgery.

Methods: We enrolled patients scheduled for coronary artery bypass grafting or valve replacement, or both, from Feb. 8, 2005, to Sept. 1, 2009. Validated measures were used to assess (a) preoperative anxiety and depression, tendency to catastrophize in the face of pain, health-related quality of life and presence of persistent pain; (b) pain intensity and interference in the first postoperative week; and (c) presence and intensity of persistent postoperative pain at 3, 6, 12 and 24 months after surgery. The primary outcome was the presence of persistent postoperative pain during 24 months of follow-up.

Results: A total of 1247 patients completed the preoperative assessment. Follow-up retention rates at 3 and 24 months were $84 \%$ and $78 \%$, respectively. The prevalence of persis-

tent postoperative pain decreased significantly over time, from $40.1 \%$ at 3 months to $22.1 \%$ at 6 months, $16.5 \%$ at 12 months and $9.5 \%$ at 24 months; the pain was rated as moderate to severe in $3.6 \%$ at 24 months. Acute postoperative pain predicted both the presence and severity of persistent postoperative pain. The more intense the pain during the first week after surgery and the more it interfered with functioning, the more likely the patients were to report persistent postoperative pain. Pre-existing persistent pain and increased preoperative anxiety also predicted the presence of persistent postoperative pain.

Interpretation: Persistent postoperative pain of nonanginal origin after cardiac surgery affected a substantial proportion of the study population. Future research is needed to determine whether interventions to modify certain risk factors, such as preoperative anxiety and the severity of pain before and immediately after surgery, may help to minimize or prevent persistent postoperative pain.
\end{abstract}

$\mathrm{P}$ ostoperative pain that persists beyond the normal time for tissue healing ( $>3 \mathrm{mo}$ ) is increasingly recognized as an important complication after various types of surgery and can have serious consequences on patients' daily living. ${ }^{1-3}$ Cardiac surgeries, such as coronary artery bypass grafting $(\mathrm{CABG})$ and valve replacement, rank among the most frequently performed interventions worldwide. ${ }^{4}$ They aim to improve survival and quality of life by reducing symptoms, including anginal pain. However, persistent postoperative pain of nonanginal origin has been reported in $7 \%$ to $60 \%$ of patients following these surgeries..$^{5-23}$ Such variability is common in other types of major surgery and is due mainly to differences in the definition of persistent postoperative pain, study design, data collection methods and duration of follow-up. ${ }^{1-3,24}$

Few prospective cohort studies have examined the exact time course of persistent postoperative pain after cardiac surgery, and follow-up has always been limited to a year or less..$^{9,14,25}$ Factors that put patients at risk of this type of problem are poorly understood. ${ }^{26}$ Studies have reported inconsistent results regarding the contribution of age, sex, body mass index, preoperative angina, surgical technique, grafting site, postoperative complications or level of opioid consumption after surgery. ${ }^{5-7,9,13,14,16-19,21-23,25,27}$ Only
Competing interests: None declared.

This article has been peer reviewed.

Correspondence to: Manon Choinière, manon.choiniere @umontreal.ca

CMAJ 2014. DOI:10.1503 /cmaj.131012 
1 study investigated the role of chronic nonanginal pain before surgery as a contributing factor, ${ }^{21}$ 5 others prospectively assessed the association between persistent postoperative pain and acute pain intensity in the first postoperative week but reported conflicting results. ${ }^{13,14,21,22,25}$ All of the above studies were carried out in a single hospital and included relatively small samples. None of the studies examined the contribution of psychological factors such as levels of anxiety and depression before cardiac surgery, although these factors have been shown to influence acute or persistent postoperative pain in other types of surgery. ${ }^{1,24,28,29}$

We conducted a prospective multicentre cohort study (the CARD-PAIN study) to determine the prevalence of persistent postoperative pain of nonanginal origin up to 24 months after cardiac surgery and to identify risk factors for the presence and severity of the condition.

\section{Methods}

\section{Study design and population}

We carried out an observational prospective study involving a large cohort of patients undergoing cardiac surgery from Feb. 8, 2005, to Sept. 1, 2009, and followed up for 24 months. Recruitment took place in 4 Canadian universityaffiliated cardiac surgery centres (the Montreal Heart Institute, the Peter Munk Cardiac Centre, the Institut universitaire de cardiologie et de pneumologie de Québec and the Maritime Heart Center). The study was approved by the research ethics board of each institution.

Experienced research assistants (nurses or respiratory therapists) screened patients for study eligibility in the preadmission clinic in the 4 weeks before surgery. Patients were included if they were 18 years or older; they were undergoing elective $\mathrm{CABG}$ or valve replacement, or both, via median sternotomy for the first time; and they had never undergone thoracotomy or mastectomy. They were excluded if they could not complete the questionnaires because of physical or mental incapacity or had insufficient knowledge of French or English.

\section{Data collection}

All consenting participants took part in a structured interview conducted by the research nurses or respiratory therapists. Patient demographics and body mass index were recorded in addition to the following study measures, all of which had well-established validity and reliability. The Canadian Cardiovascular Society grading scale ${ }^{30}$ was used to document the severity of preoperative angina in terms of physical limitations. The presence of persistent nonanginal pain (e.g., migraine, arthritic pain) for at least 3 months before surgery was also assessed. Because pain involves not only a biological component but also important emotional and cognitive dimensions, the Hospital Anxiety and Depression Scale $^{31}$ was used to measure patients' anxiety and depression levels. The Pain Catastrophizing Scale $^{32}$ was used to assess patients' negative cognitive-affective responses to pain. Finally, the SF-12v2 Health Survey ${ }^{33}$ was used to assess preoperative physical and mental health-related quality of life.

Data collection during the hospital stay and at follow-up (at 3, 6, 12 and 24 months) was done by the research nurses and respiratory therapists involved in patient recruitment and initial interviews. In some study sites, additional research assistants (graduate students) were hired to collect data on weekends or during evenings. All efforts were made to ensure uniformity of the procedures at each site (e.g., standardized comprehensive training by one person [the research nurse coordinator], use of a structured face-to-face interview protocol to collect perioperative data across the study sites and use of a structured telephone interview protocol at follow-up in all sites).

At 24, 48 and 72 hours and 7 days after surgery, patients were asked to rate the intensity of their worst and average postoperative pain on movement during the preceding 24 hours using a standard numerical rating scale $(0=$ no pain, 10 $=$ worst possible pain) ${ }^{34}$ On day 7 , the pain interference items of the Brief Pain Inventory were administered to evaluate the extent to which patients' pain was interfering with their general activity, mood, walking, work, relations with others, sleep and enjoyment of life $(0=$ does not interfere, $10=$ completely interferes $).{ }^{35} \mathrm{We}$ added 3 items to this assessment: deep breathing or coughing, appetite and concentration. A total score was calculated from the sum of all the items. Participants discharged home before day 7 were telephoned to collect their pain ratings and interference scores.

The following medical and surgical data during the hospital stays were extracted from patient charts by the research nurses: type and duration of surgery, postoperative complications, length of stay in the intensive care unit (ICU), time in hospital after discharge from the ICU and use of analgesic medications. Total doses of opioids from day 1 to 7 were converted into milligrams of parenteral morphine equivalents.

At 3, 6, 12 and 24 months after surgery, patients were interviewed by telephone to measure the presence of persistent postoperative pain 
using a structured interview protocol. Pain was defined as persistent postoperative pain if it met the following 3 criteria: it first appeared after surgery; it was not related to pain felt before surgery (e.g., anginal pain) or to other causes (e.g., infection); and it was present for at least 3 months. ${ }^{3}$ Patients who met all 3 criteria were asked to rate the intensity of their average pain in the past 7 days using the numerical rating scale $(0=$ no pain, $10=$ worst possible pain $){ }^{34}$

\section{Outcome measures}

The primary outcome was the presence of persistent postoperative pain during 24 months of follow-up. The secondary outcome was the severity of this type of pain in terms of intensity on the numerical rating scale.

\section{Statistical analysis}

As in previous studies in the cardiac surgery field, $, 14,19,22,36$ we defined acute and persistent post-

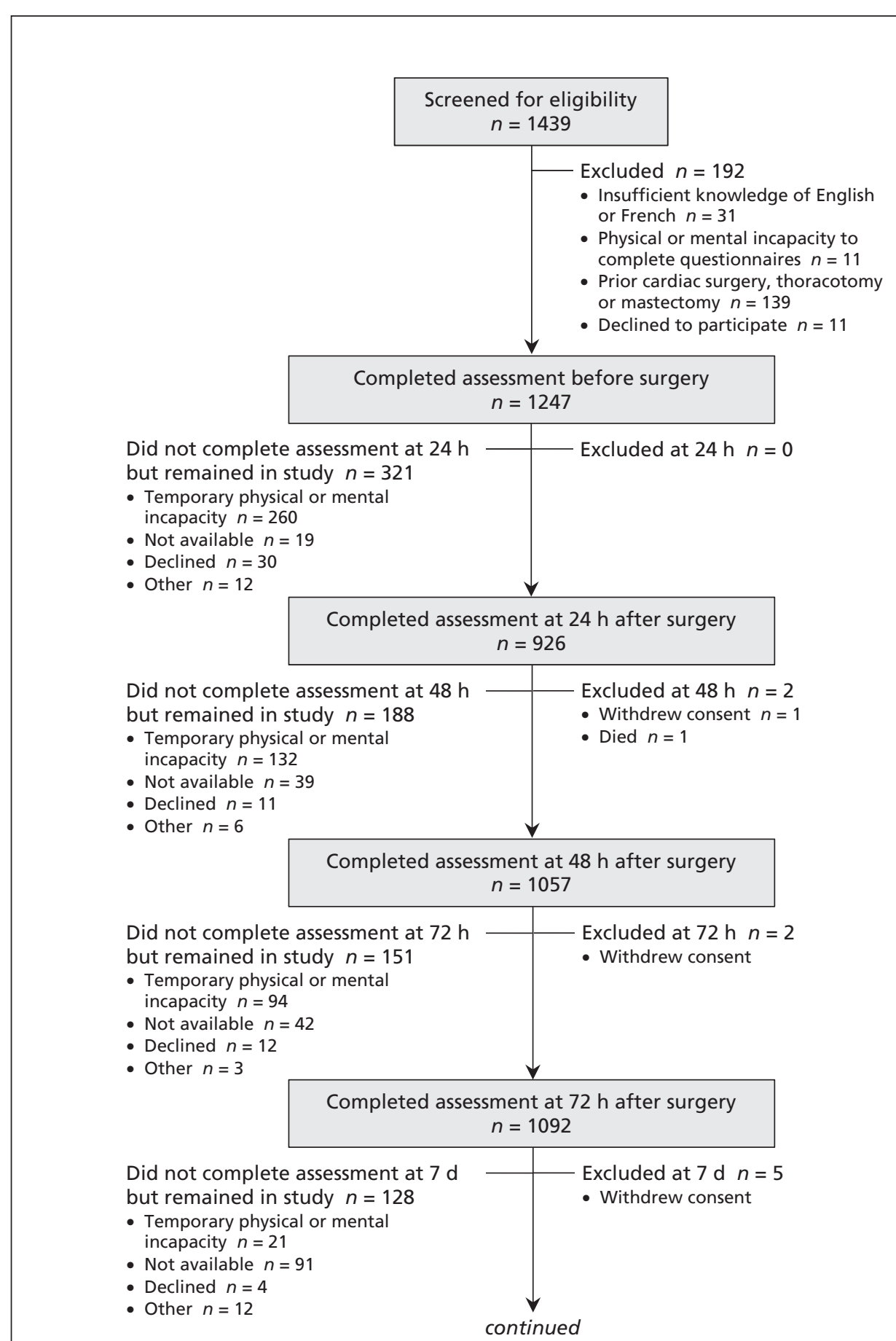

Figure 1 (part 1 of 2): Study flow. 
Figure 1 continued

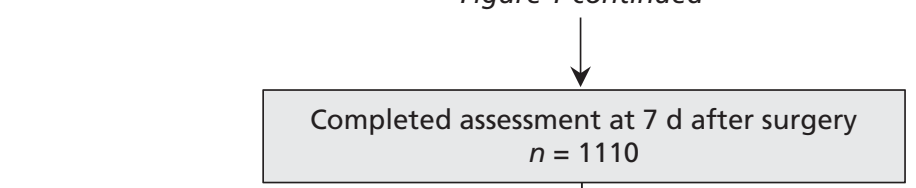

Did not complete assessment at 3 mo $\quad$ Excluded at 3 mo $n=32$

but remained in study $n=152$

- Temporary physical or mental

incapacity $n=3$

- Not available $n=139$

- Declined $n=2$

- Other $n=8$

- Withdrew consent $n=14$

- Died $n=7$

- Lost contact $n=2$

- Physical or mental incapacity $n=9$

Completed assessment at 3 mo after surgery

\begin{tabular}{l|l}
\multicolumn{2}{|c|}{$n=1054$} \\
\begin{tabular}{l|l} 
Did not complete assessment at 6 mo & Excluded at 6 mo $n=65$ \\
but remained in study $n=118$ & - Withdrew consent $n=9$
\end{tabular}
\end{tabular}

but remained in study $n=118$

- Temporary physical or mental

incapacity $n=4$

- Not available $n=107$

- Other $n=7$

- Died $n=2$

- Lost contact $n=54$

Completed assessment at 6 mo after surgery

\begin{tabular}{|l|l|}
\multicolumn{2}{|c|}{$n=1023$} \\
Did not complete assessment at $12 \mathrm{mo}-$ & Excluded at $12 \mathrm{mo} n=43$ \\
\hline
\end{tabular}

but remained in study $n=87$

- Temporary physical or mental

incapacity $n=1$

- Not available $n=77$

- Declined $n=2$

- Other $n=7$

- Withdrew consent $n=5$

- Died $n=2$

- Lost contact $n=34$

- Physical or mental incapacity $n=1$

- Other $n=1$

-

Completed measurements 12 mo after surgery $n=1011$

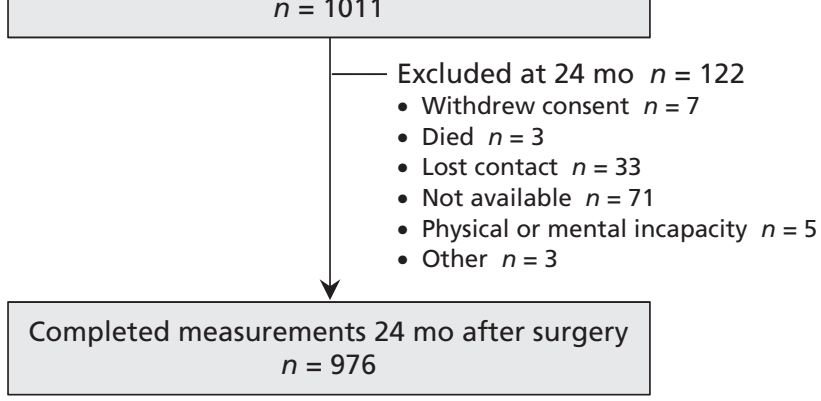

Figure 1 (part 2 of 2): Study flow.

operative pain as moderate to severe if the patient reported a pain intensity score of 4 or higher out of 10 on the numerical rating scale.

To identify participant characteristics related to persistent postoperative pain over time, we used generalized estimating equation (GEE) models for binary outcomes, which provide robust estimates while adjusting for lack of independence due to sampling of multiple observations per patient and multiple patients from the same study site. ${ }^{37}$ In the models, we included only patients for whom data were available on demographic information and preoperative measurements, pain ratings on postoperative day 3 (when increased ambulation usually results in peak pain levels ${ }^{36}$ ), pain interference scores on day 7 and information from at least 1 follow-up interview at 3,6,12 or 24 months after surgery. All available data on patients meeting inclusion criteria were used in the models regardless if 1 to 3 follow-up interviews were missing. There was no imputation for missing data or time points.

The models examined the effects of each potential predictor, time and the interaction between the variables and time. Variables or interaction terms significant at a $p$ value of 0.10 or less were included in the multivariable models. Collinear variables were identified, and the 
variable with the smaller effect size was omitted from the multivariable equation.

Model fit and covariance structure were assessed with use of the QIC (quasi-likelihood under independence model criterion) statistic and regression diagnostics (e.g., standardized Pearson residuals, leverages, changes in deviance).

\section{Results}

A total of 1247 patients were enrolled, and 976 $(78.3 \%)$ of them were available for follow-up 24 months after surgery (Figure 1). A total of 975 patients $(78.2 \%)$ who participated in the preoperative interview were included in the GEE models because they also provided the requisite postoperative measures and completed at least 1 follow-up interview at 3, 6, 12 or 24 months after surgery. Most of the 975 patients were men $(79.0 \%)$ and underwent CABG with or without valve replacement (76.6\%); the mean age was 61.9 (range 21-86) years (Table 1).

The proportion of all participants who rated their worst pain on movement during the preceding 24 hours as moderate to severe remained above $65 \%$ across all time points in the first week after surgery (Table 2, Figure 2). A substantial proportion of participants also rated their average 24-hour pain on movement as moderate to severe at the same time points; the proportion was $43 \%$ on day 7 .

Of the patients who completed assessments at each follow-up point, $40.1 \%$ reported experiencing persistent postoperative pain of any intensity ( $>0$ out of 10) 3 months after surgery. The proportion decreased significantly over time $(p<0.001)$ : it was relatively stable at 6 months $(22.1 \%)$ and 12 months $(16.5 \%)$ and then reached $9.5 \%$ at 24 months (Table 3, Figure 3). When taking pain intensity into account, the prevalence of moderate to severe persistent postoperative pain in the 7 days before the follow-up interview also declined over time $(p<0.001)$, from $14.1 \%$ at 3 months to $3.6 \%$ at 24 months (Table 3, Figure 3).

In the multivariable GEE regression model, factors that emerged as significant independent predictors of persistent postoperative pain of any intensity were young age, persistent nonanginal pain before surgery, anxiety before surgery, moderate to severe acute pain on the third postoperative day and increased interference of the pain with various aspects of daily living 1 week after surgery (Table 4). A significant negative association was found between duration of surgery and persistent postoperative pain.

When we used the GEE model to examine predictors of persistent postoperative pain of moderate to severe intensity, the only ones similar to predictors of any persistent postoperative pain were moderate to severe acute pain on the third postoperative day (adjusted odds ratio [OR] $2.67,95 \%$ confidence interval [CI] 1.74-4.11) and the pain's interference with various aspects of daily living 1 week after surgery (OR 1.03, 95\% CI 1.02-1.04) (Table 5). Sex but not age was a significant independent predictor, with women being more likely than men to report persistent postoperative pain of moderate to severe intensity

Table 1: Characteristics of patients with persistent postoperative pain of nonanginal origin following cardiac surgery $\left(n=975^{*}\right)$

\begin{tabular}{|c|c|}
\hline Characteristic & $\begin{array}{c}\text { Mean } \pm \text { SD or } \\
\text { no. }(\%) \text { of patients* }\end{array}$ \\
\hline Age, yr & $61.9 \pm 10.2$ \\
\hline Sex, male & $770(79.0)$ \\
\hline \multicolumn{2}{|l|}{ Education level } \\
\hline Elementary school & $150(15.4)$ \\
\hline High school & $348(35.7)$ \\
\hline College or technical school & $245(25.1)$ \\
\hline University & $232(23.8)$ \\
\hline Body mass index & $28.7 \pm 4.8$ \\
\hline \multicolumn{2}{|l|}{ CCS grading of anginat } \\
\hline Class I & $74(7.6)$ \\
\hline Class II & $293(30.1)$ \\
\hline Class III & $182(18.7)$ \\
\hline Class IV & $63(6.5)$ \\
\hline NA & $363(37.2)$ \\
\hline \multicolumn{2}{|l|}{ Persistent nonanginal pain before surgery } \\
\hline Yes & $326(33.4)$ \\
\hline No & $649(66.6)$ \\
\hline \multicolumn{2}{|l|}{ Types of surgery } \\
\hline CABG alone & $640(65.6)$ \\
\hline Valve replacement alone & $228(23.4)$ \\
\hline CABG and valve replacement & $107(11.0)$ \\
\hline \multicolumn{2}{|l|}{ Postoperative complications } \\
\hline Yes & $541(55.5)$ \\
\hline No & $434(44.5)$ \\
\hline Duration of surgery, $\mathrm{h}$ & $3.4 \pm 1.0$ \\
\hline Time in ICU, $d$ & $1.4 \pm 1.0$ \\
\hline Time in hospital after discharge from ICU, d & $5.2 \pm 2.7$ \\
\hline Total dose of opioids during first wk after surgery, mg & $98.5 \pm 63.0$ \\
\hline \multicolumn{2}{|c|}{$\begin{array}{l}\text { Note: CABG = coronary artery bypass grafting, CCS = Canadian Cardiovascular Society, ICU = } \\
\text { intensive care unit, NA = not applicable, SD = standard deviation. } \\
\text { *Only the } 975 \text { patients whose data were included in the regression analyses are represented } \\
\text { in this table (i.e., those who provided demographic information, preoperative pain } \\
\text { measurements, pain ratings on postoperative day } 3 \text {, pain interference scores on day } 7 \text {, and at } \\
\text { least } 1 \text { follow-up interview at } 3,6,12 \text { or } 24 \text { mo after surgery). } \\
\text { tClass I = angina only during strenuous or prolonged physical activity; class II = angina only } \\
\text { during vigorous physical activity; class III = symptoms with everyday living activities; class IV = } \\
\text { inability to perform any activity without angina, or angina at rest. } \\
\text { fExpressed in milligrams of parenteral morphine equivalents. }\end{array}$} \\
\hline
\end{tabular}


at all follow-up times (adjusted OR 1.62, 95\% CI 1.11-2.35). A significant association was found between time spent in the ICU and persistent postoperative pain severity (adjusted OR 1.19, 95\% CI 1.05-1.36). A significant negative association was found between time spent in hospital after the ICU and persistent pain: the longer the stay in hospital after discharge from the ICU, the less likely patients were to report moderate to severe persistent postoperative pain (adjusted OR $0.86,95 \%$ CI $0.78-0.95)$.

\section{Interpretation}

In our study, $9.5 \%$ of participants experienced persistent postoperative pain at 24 months after surgery. This proportion decreased to $3.6 \%$ when pain of moderate to severe intensity was considered. Results at earlier follow-up points are con-

\begin{tabular}{|c|c|c|}
\hline \multirow[b]{2}{*}{ Time after surgery } & \multicolumn{2}{|c|}{$\begin{array}{c}\text { Pain rated as moderate to severe; } \\
\% \text { (no.) of patientst }\end{array}$} \\
\hline & Worst & Average \\
\hline $24 \mathrm{~h}$ & $85.0(787 / 926)$ & $64.0(593 / 926)$ \\
\hline $48 \mathrm{~h}$ & $86.0(909 / 1057)$ & $68.0(719 / 1057)$ \\
\hline $72 \mathrm{~h}$ & $74.0(808 / 1092)$ & $54.0(590 / 1092)$ \\
\hline Day 7 & $65.0(722 / 1110)$ & $43.0(477 / 1110)$ \\
\hline
\end{tabular}

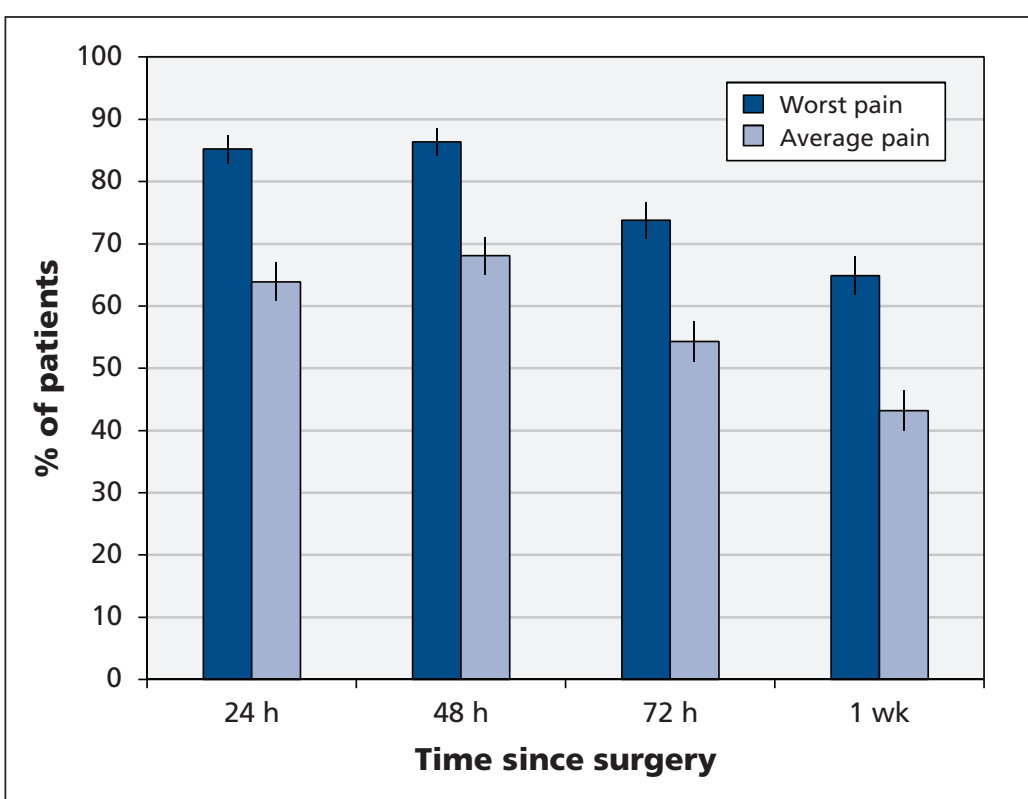

Figure 2: Proportion of patients who rated their worst and average pain on movement during the previous $\mathbf{2 4}$ hours as moderate to severe in the first week after surgery. Error bars represent $95 \%$ confidence intervals. sistent with those reported in several prospective studies of shorter duration among cardiac surgery patients. ${ }^{9,13,14,20,21,25}$

These prevalence rates are not negligible given that more than 400000 patients undergo CABG annually in the United States ${ }^{4}$ and that persistent postoperative pain affects patients' health-related quality of life. ${ }^{7-9,19}$ The risk of persistent postoperative pain should be discussed with patients during preoperative counselling and perhaps included in informed consent for surgery.,38 Surgeons and cardiologists need to assess the presence and severity of persistent postoperative pain at follow-up visits. Patients may not mention their pain because attention is focused on their cardiac condition. Clinicians' lack of familiarity with the prevalence or potential treatments of persistent postoperative pain may result in no or deficient pain management. $^{26}$

Consistent with observations made in car$\operatorname{diac}^{14,22}$ and noncardiac surgery patient cohorts, ${ }^{1-3,24}$ we showed that the intensity of acute postoperative pain was a significant predictor of both the presence and the severity of persistent postoperative pain. Irrespective of study sites, patients with higher ratings for acute pain and interference with daily functioning in the first week after surgery were more likely to report persistent postoperative pain at 24 months.

That pain can predict later pain is further illustrated by our finding that patients who had chronic nonanginal pain before surgery were at significantly increased risk of persistent postoperative pain. This result is consistent with those from reports in noncardiac surgery cohorts ${ }^{1-3,24}$ and suggests the manifestation of some predisposing factors. However, it is unknown whether the development of persistent postoperative pain is causally linked to the presence of preexisting chronic pain or the severity of acute postoperative pain (e.g., by central sensitization or development of a pain memory), or whether this link is simply associative (i.e., they all are influenced by similar risk factors, such as genetic determinants). ${ }^{1-3,24}$ The literature on the prevention of persistent postoperative pain through the provision of adequate acute pain relief does not really shed light on this issue, despite encouraging results for some surgical interventions. ${ }^{39}$ In cardiac surgery, the evidence to support any protective analgesic regimen is either lacking or limited. ${ }^{26}$

Other factors that predicted either the presence or severity of persistent postoperative pain included age and sex, a result that is consistent with earlier observations in cardiac surgery cohorts. ${ }^{7,9,12,18,21,22}$ Increased anxiety before surgery 
was also found to be a significant risk factor whose association with persistent postoperative pain was independent of its influence on acute postoperative pain. Assessment of anxiety levels before cardiac surgery may be beneficial, because psychological counselling, education and medical treatment, alone or in combination, may help to improve long-term outcomes of targeted patients.

As reported in previous studies, ${ }^{9,17,19,21,25,35}$ we found no significant association between the type of surgery (CABG or valve replacement, or both) and persistent postoperative pain. However, we found that the longer the surgery lasted, the less likely patients were to report any persistent postoperative pain. This finding was unexpected, and we have no explanation for it. Reviews of the existing literature on other types of surgery ${ }^{1-3,24}$ suggest an association in the opposite direction, if any. However, the studies we retrieved in the field of cardiac surgery failed to find an association between duration of the operation and persistent postoperative pain.

The length of time spent in the ICU did not predict the presence of persistent postoperative pain, but it did help to distinguish patients with moderate to severe pain from those with no or mild pain. We found a significant negative association between length of hospital stay after ICU discharge and intensity of persistent postoperative pain. It is tempting to speculate that patients who were discharged from ICU earlier were provided with insufficient analgesia and experienced more pain at home, which may have increased their risk of more intense persistent postoperative pain.

\section{Strengths and limitations}

Our study has several strengths. It was a prospective, multicentre study with a large cohort of cardiac surgery patients. Also, the follow-up was 24 months after surgery, as compared with 12 months or less in earlier studies..$^{9,14,25}$

Detailed neurophysiological examinations and quantitative sensory testing were not performed to assess the presence of sensory abnormalities in the area of surgery (e.g., hyperesthesia, hypoesthesia) in the pre- and postoperative periods. Therefore, we were unable to evaluate the potential role of altered pain processing due to intraoperative nerve injury or to some general predispositional factors in the development of persistent postoperative pain. ${ }^{1-3,24}$ Another limitation is that our results are based on self-reported pain. However, we applied rigorous definition criteria of persistent postoperative pain, ${ }^{3}$ and great care was taken to exclude the possibility that pain was continuing from a pre-existing problem including angina.

\section{Conclusion}

Persistent postoperative pain of nonanginal origin was experienced by about $10 \%$ of patients after cardiac surgery, and moderate to severe pain by about $4 \%$. Given the impact such pain may have on daily functioning and quality of life, patients should be informed about this possibility. We identified several significant risk factors of persistent postoperative pain, including 2 that can be managed (increased anxiety before surgery and acute postoperative pain in the first week after surgery). The severity of persistent preoperative pain may also be amenable to change. Future research should evaluate the

Table 3: Proportion of patients who reported experiencing any persistent postoperative pain and persistent pain of moderate to severe intensity* up to 24 mo after surgery

\begin{tabular}{|c|c|c|}
\hline \multirow{2}{*}{$\begin{array}{l}\text { Time after } \\
\text { surgery, mo }\end{array}$} & \multicolumn{2}{|c|}{ Persistent postoperative pain; \% (no.) of patientst } \\
\hline & Any & Moderate to severe \\
\hline 3 & $40.1(423 / 1054)$ & $14.1(149 / 1054)$ \\
\hline 6 & $22.1(226 / 1023)$ & $7.0(72 / 1023)$ \\
\hline 12 & $16.5(167 / 1011)$ & $6.6(67 / 1011)$ \\
\hline 24 & $9.5(93 / 976)$ & $3.6(35 / 976)$ \\
\hline
\end{tabular}

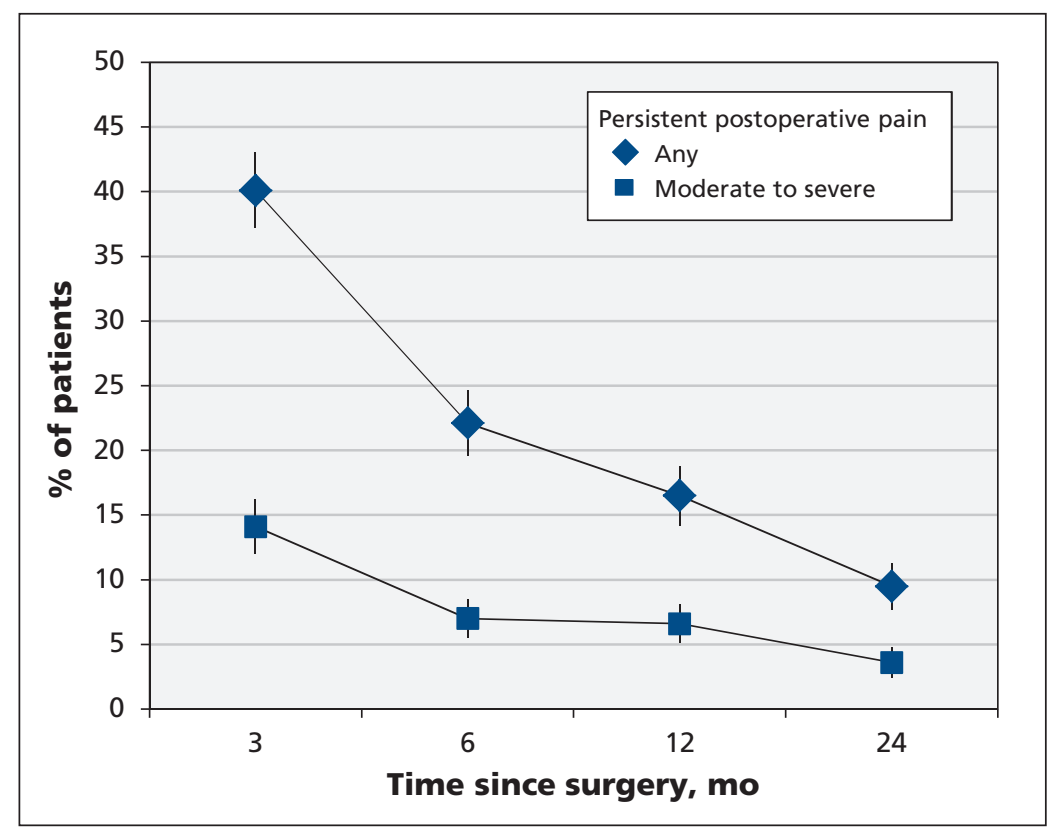

Figure 3: Proportion of patients who reported experiencing persistent postoperative pain up to 24 months after surgery. Error bars represent $95 \%$ confidence intervals. 
Table 4: Results of generalized estimating equation (logit) regression analyses to predict presence of any persistent postoperative nonanginal pain over time $\left(n=975^{*}\right)$

\begin{tabular}{|c|c|c|}
\hline Variable & Crude OR $(95 \% \mathrm{Cl})$ & Adjusted OR† $(95 \% \mathrm{Cl})$ \\
\hline \multicolumn{3}{|l|}{ Potential predictors before surgery } \\
\hline Female sex & $1.61(1.26-2.07)$ & $1.13(0.85-1.50)$ \\
\hline \multicolumn{3}{|l|}{ Age group, yr (v. $\geq 76$ yr) } \\
\hline $21-55$ & $2.51(1.64-3.83)$ & 1.87 (1.09-3.19) \\
\hline $56-65$ & $1.90(1.27-2.85)$ & $1.43(0.85-2.41)$ \\
\hline $66-75$ & $1.57(1.00-2.40)$ & $1.28(0.76-2.15)$ \\
\hline \multicolumn{3}{|l|}{ Education level (v. university) } \\
\hline Elementary school & $0.98(0.70-1.39)$ & - \\
\hline High school & $0.92(0.69-1.22)$ & - \\
\hline College or technical school & $0.90(0.66-1.22)$ & - \\
\hline Body mass index, continuous & $1.02(0.99-1.04)$ & - \\
\hline \multicolumn{3}{|l|}{ CCS grading scale of angina (v. class I) $¥$} \\
\hline Class II & $0.76(0.50-1.16)$ & - \\
\hline Class III & $0.75(0.48-1.16)$ & - \\
\hline Class IV & $1.58(0.93-2.68)$ & - \\
\hline NA & $0.71(0.47-1.08)$ & - \\
\hline Persistent nonanginal pain before surgery (v. none) & $1.57(1.26-1.96)$ & $1.44(1.12-1.86)$ \\
\hline HADS Anxiety, continuous & $1.09(1.06-1.11)$ & $1.04(1.00-1.09)$ \\
\hline HADS Depression, continuous & $1.06(1.03-1.10)$ & $0.98(0.93-1.04)$ \\
\hline Pain Catastrophizing Scale score, continuous & $1.02(1.01-1.03)$ & $1.00(0.99-1.02)$ \\
\hline SF-12v2 mental health summary score, continuous & $0.95(0.93-0.97)$ & $1.02(0.98-1.07)$ \\
\hline SF-12v2 physical health summary score, continuous & $0.95(0.92-0.97)$ & $0.99(0.95-1.02)$ \\
\hline \multicolumn{3}{|l|}{ Potential predictors during or after surgery } \\
\hline \multicolumn{3}{|l|}{ Type of surgery ( $v$. CABG and valve replacement) } \\
\hline CABG alone & $1.14(0.79-1.64)$ & - \\
\hline Valve replacement alone & $1.24(0.83-1.85)$ & - \\
\hline Duration of surgery, $h$, continuous & $0.84(0.75-0.94)$ & $0.85(0.75-0.96)$ \\
\hline Time in ICU, d, continuous & $1.03(0.96-1.11)$ & - \\
\hline Time in hospital after discharge from ICU, $d$, continuous & $0.95(0.91-1.00)$ & $0.95(0.90-1.01)$ \\
\hline Postoperative complications (v. none) & $0.86(0.69-1.06)$ & - \\
\hline $\begin{array}{l}\text { Average pain in previous } 24 \mathrm{~h} \text { rated as moderate to } \\
\text { severe§ on day } 3 \text { after surgery ( } \mathrm{v} \text {. none) }\end{array}$ & $2.23(1.78-2.79)$ & $1.48(1.10-2.00)$ \\
\hline $\begin{array}{l}\text { Worst pain in previous } 24 \mathrm{~h} \text { rated as moderate to } \\
\text { severe } \S \text { on day } 3 \text { after surgery ( } \mathrm{v} \text {. none) }\end{array}$ & $2.58(1.94-3.44)$ & $1.69(1.16-2.47)$ \\
\hline $\begin{array}{l}\text { Total BPI pain interference score on day } 7 \text { after } \\
\text { surgery, continuous }\end{array}$ & $1.04(1.03-1.05)$ & $1.03(1.02-1.04)$ \\
\hline $\begin{array}{l}\text { Total dose of opioids } 1 \text { administered during first wk } \\
\text { after surgery, continuous per } 10 \text {-unit dose }\end{array}$ & $1.02(1.00-1.04)$ & $1.00(1.00-1.00)$ \\
\hline \multicolumn{3}{|c|}{ 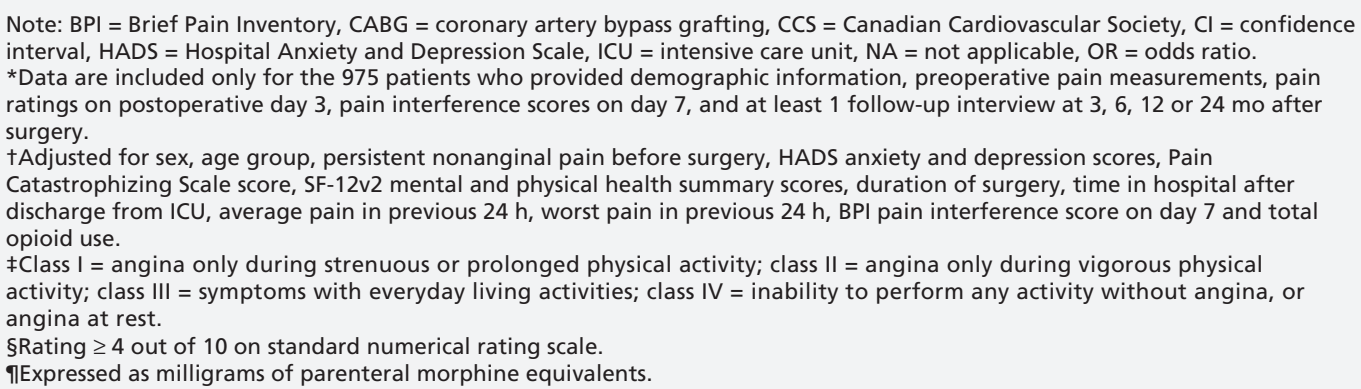 } \\
\hline
\end{tabular}


Table 5: Results of generalized estimating equation (logit) regression analyses to predict persistent postoperative nonanginal pain of moderate to severe intensity over time $\left(n=975^{*}\right)$

\begin{tabular}{|c|c|c|}
\hline Variable & Crude OR $(95 \% \mathrm{Cl})$ & Adjusted OR† $(95 \% \mathrm{Cl}$ \\
\hline \multicolumn{3}{|l|}{ Potential predictors before surgery } \\
\hline Female sex & $2.09(1.50-2.91)$ & $1.62(1.11-2.35)$ \\
\hline \multicolumn{3}{|l|}{ Age group, yr (v. $\geq 76$ yr) } \\
\hline $21-55$ & $1.97(1.00-3.89)$ & - \\
\hline $56-65$ & $1.71(0.88-3.31)$ & - \\
\hline $66-75$ & $1.33(0.68-2.63)$ & - \\
\hline \multicolumn{3}{|l|}{ Education level (v. university) } \\
\hline Elementary school & $1.58(0.94-2.64)$ & - \\
\hline High school & $1.29(0.83-1.99)$ & - \\
\hline College or technical school & $0.94(0.57-1.56)$ & - \\
\hline Body mass index, continuous & $1.02(0.99-1.06)$ & - \\
\hline \multicolumn{3}{|l|}{ CCS grading scale of angina ( $v$. class I) $\ddagger$} \\
\hline Class II & $1.35(0.73-2.51)$ & $1.08(0.56-2.09)$ \\
\hline Class III & $1.67(0.87-3.24)$ & $1.32(0.65-2.69)$ \\
\hline Class IV & $3.44(1.67-7.08)$ & $1.81(0.83-3.92)$ \\
\hline NA & $1.17(0.63-2.16)$ & $1.03(0.54-1.96)$ \\
\hline $\begin{array}{l}\text { Persistent nonanginal pain before surgery } \\
\text { (v. none) }\end{array}$ & $1.40(1.01-1.94)$ & $1.20(0.85-1.71)$ \\
\hline HADS Anxiety, continuous & $1.11(1.07-1.15)$ & $1.04(0.99-1.10)$ \\
\hline HADS Depression, continuous & $1.12(1.07-1.16)$ & $1.00(0.92-1.07)$ \\
\hline Pain Catastrophizing Scale score, continuous & $1.04(1.02-1.05)$ & $1.01(0.99-1.03)$ \\
\hline $\begin{array}{l}\text { SF-12v2 mental health summary score, } \\
\text { continuous }\end{array}$ & $0.91(0.88-0.94)$ & $0.98(0.92-1.04)$ \\
\hline SF-12v2 physical health summary score, & $0.90(0.87-0.94)$ & $0.97(0.92-1.02)$ \\
\hline
\end{tabular}

continuous

Potential predictors during or after surgery

Type of surgery (v. CABG and valve replacement)

\begin{tabular}{|c|c|c|}
\hline CABG alone & $1.35(0.80-2.28)$ & - \\
\hline Valve replacement alone & $1.25(0.70-2.23)$ & - \\
\hline Duration of surgery, $h$, continuous & $0.88(0.74-1.06)$ & - \\
\hline Time in ICU, d, continuous & $1.07(0.99-1.14)$ & $1.19(1.05-1.36)$ \\
\hline $\begin{array}{l}\text { Time in hospital after discharge from ICU, d, } \\
\text { continuous }\end{array}$ & $0.88(0.81-0.96)$ & $0.86(0.78-0.95)$ \\
\hline Postoperative complications (v. none) & $0.76(0.56-1.05)$ & $0.90(0.62-1.30)$ \\
\hline $\begin{array}{l}\text { Average pain in previous } 24 \mathrm{~h} \text { rated as moderate to } \\
\text { severe§ on day } 3 \text { after surgery ( } \mathrm{v} \text {. none) }\end{array}$ & $3.92(2.69-5.70)$ & $2.67(1.74-4.11)$ \\
\hline $\begin{array}{l}\text { Total BPI pain interference score on day } 7 \text { after } \\
\text { surgery, continuous }\end{array}$ & $1.04(1.03-1.06)$ & $1.03(1.02-1.04)$ \\
\hline $\begin{array}{l}\text { Total dose of opioids } \text { administered during first wk } \\
\text { after surgery, continuous per } 10 \text {-unit dose }\end{array}$ & $1.02(1.00-1.04)$ & $1.00(1.00-1.00)$ \\
\hline
\end{tabular}

Note: $\mathrm{BPI}=$ Brief Pain Inventory, $\mathrm{CABG}=$ coronary artery bypass grafting, $\mathrm{CCS}=\mathrm{Canadian}$ Cardiovascular Society, $\mathrm{Cl}=\mathrm{confidence}$ interval, HADS = Hospital Anxiety and Depression Scale, ICU = intensive care unit, NA = not applicable, OR = odds ratio.

*Data are included only for the 975 patients who provided demographic information, preoperative pain measurements, pain ratings on postoperative day 3, pain interference scores on day 7 , and at least one follow-up interview at 3, 6, 12 or 24 mo after surgery.

†Adjusted for sex, CCS class, persistent nonanginal pain before surgery, HADS anxiety and depression scores, Pain

Catastrophizing Scale score, SF-12v2 mental and physical health summary scores, time in ICU, time in hospital after discharge

from ICU, average pain in previous $24 \mathrm{~h}$, BPI pain interference score on day 7 and total opioid use.

$\neq$ Class I = angina only during strenuous or prolonged physical activity; class II = angina only during vigorous physical activity; class III = symptoms with everyday living activities; class IV = inability to perform any activity without angina, or angina at rest.

§Rating $\geq 4$ out of 10 on standard numerical rating scale.

ПExpressed as milligrams of parenteral morphine equivalents. 
effects of such interventions in a balanced regimen of multimodal treatments. Well-designed, carefully controlled studies are needed to determine whether persistent postoperative pain can be minimized or prevented and to provide patients with optimal treatment in the presence of this type of complication.

\section{References}

1. Katz J, Seltzer Z. Transition from acute to chronic postsurgical pain: risk factors and protective factors. Expert Rev Neurother 2009;9:723-44.

2. Kehlet H, Jensen TS, Woolf CJ. Persistent postsurgical pain: risk factors and prevention. Lancet 2006;367:1618-25.

3. Macrae WA. Chronic post-surgical pain: 10 years on. Br J Anaesth 2008;101:77-86

4. Roger VL, Go AS, Lloyd-Jones DM, et al. Heart disease and stroke statistics - 2012 update: a report from the American Heart Association. Circulation 2012;125:e2-220.

5. Bar-El Y, Gilboa B, Unger N, et al. Skeletonized versus pedicled internal mammary artery: impact of surgical technique on post CABG surgery pain. Eur J Cardiothorac Surg 2005;27:1065-9.

6. Boodhwani M, Lam BK, Nathan HJ, et al. Skeletonized internal thoracic artery harvest reduces pain and dysesthesia and improves sternal perfusion after coronary artery bypass surgery: a randomized, double-blind, within-patient comparison. Circulation 2006;114:766-73.

7. Bruce J, Drury N, Poobalan AS, et al. The prevalence of chronic chest and leg pain following cardiac surgery: a historical cohort study. Pain 2003;104:265-73.

8. Eisenberg E, Pultorak Y, Pud D, et al. Prevalence and characteristics of post coronary artery bypass graft surgery pain (PCP). Pain 2001;92:11-7.

9. Gjeilo KH, Klepstad P, Wahba A, et al. Chronic pain after cardiac surgery: a prospective study. Acta Anaesthesiol Scand 2010; 54:70-8.

10. Ho SC, Royse CF, Royse AG, et al. Persistent pain after cardiac surgery: an audit of high thoracic epidural and primary opioid analgesia therapies. Anesth Analg 2002;95:820-3.

11. Jensen MK, Andersen C. Can chronic poststernotomy pain after cardiac valve replacement be reduced using thoracic epidural analgesia? Acta Anaesthesiol Scand 2004;48:871-4.

12. Kalso E, Mennander S, Tasmuth T, et al. Chronic post-sternotomy pain. Acta Anaesthesiol Scand 2001;45:935-9.

13. King KM, Parry M, Southern D, et al. Women's Recovery from Sternotomy-Extension (WREST-E) study: examining long-term pain and discomfort following sternotomy and their predictors. Heart 2008;94:493-7.

14. Lahtinen P, Kokki H, Hynynen M. Pain after cardiac surgery: a prospective cohort study of 1-year incidence and intensity. Anesthesiology 2006;105:794-800.

15. Mailis A, Umana M, Feindel CM. Anterior intercostal nerve damage after coronary artery bypass graft surgery with use of internal thoracic artery graft. Ann Thorac Surg 2000;69:1455-8.

16. Markman PL, Rowland MA, Leong JY, et al. Skeletonized internal thoracic artery harvesting reduces chest wall dysesthesia after coronary bypass surgery. J Thorac Cardiovasc Surg 2010;139:674-9.

17. Meyerson J, Thelin S, Gordh T, et al. The incidence of chronic post-sternotomy pain after cardiac surgery - a prospective study. Acta Anaesthesiol Scand 2001;45:940-4.

18. Steegers MA, van de Luijtgaarden A, Noyez L, et al. The role of angina pectoris in chronic pain after coronary artery bypass graft surgery. J Pain 2007;8:667-73.

19. Taillefer MC, Carrier M, Belisle S, et al. Prevalence, characteristics, and predictors of chronic nonanginal postoperative pain after a cardiac operation: a cross-sectional study. J Thorac Cardiovasc Surg 2006;131:1274-80.

20. Ucak A, Onan B, Sen H, et al. The effects of gabapentin on acute and chronic postoperative pain after coronary artery bypass graft surgery. J Cardiothorac Vasc Anesth 2011;25:824-9.

21. van Gulik L, Ahlers SJ, van de Garde EM, et al. Remifentanil during cardiac surgery is associated with chronic thoracic pain 1 yr after sternotomy. Br J Anaesth 2012;109:616-22.

22. van Gulik L, Janssen LI, Ahlers SJ, et al. Risk factors for chronic thoracic pain after cardiac surgery via sternotomy. Eur J Cardiothorac Surg 2011;40:1309-13.

23. Wiklund L, Johansson M, Bugge M, et al. Early outcome and graft patency in mammary artery grafting of left anterior descending artery with sternotomy or anterior minithoracotomy. Ann Thorac Surg 2000;70:79-83.
24. VanDenKerkhof EG, Peters ML, Bruce J. Chronic pain after surgery: Time for standardization? A framework to establish core risk factor and outcome domains for epidemiological studies. Clin J Pain 2013;29:2-8.

25. Lee W, Yan YY, Jensen MP, et al. Predictors and patterns of chronic pain three months after cardiac surgery in Taiwan. Pain Med 2010;11:1849-58.

26. Mazzeffi M, Khelemsky Y. Poststernotomy pain: a clinical review. J Cardiothorac Vasc Anesth 2011;25:1163-78.

27. Eng J, Wells FC. Morbidity following coronary artery revascularisation with the internal mammary artery. Int J Cardiol 1991; 30:55-9.

28. Theunissen M, Peters ML, Bruce J, et al. Preoperative anxiety and catastrophizing: a systematic review and meta-analysis of the association with chronic postsurgical pain. Clin J Pain 2012; 28:819-41.

29. Hinrichs-Rocker A, Schulz K, Jarvinen I, et al. Psychosocial predictors and correlates for chronic post-surgical pain (CPSP) - a systematic review. Eur J Pain 2009;13:719-30.

30. Campeau L. Letter: Grading of angina pectoris. Circulation 1976;54:522-3

31. Zigmond AS, Snaith RP. The hospital anxiety and depression scale. Acta Psychiatr Scand 1983;67:361-70.

32. Sullivan MJL, Bishop S, Pivik J. The Pain Catastrophizing Scale: development and validation. Psychol Assess 1995;7:524-32

33. Ware J Jr, Kosinski M, Keller SD. A 12-Item Short-Form Health Survey: construction of scales and preliminary tests of reliability and validity. Med Care 1996;34:220-33.

34. Jensen PP, Karoly P. Self-report scales and procedures for assessing pain in adults. In: Turk DC, Melzack R, editors. Handbook of pain assessment. 2nd ed. New York (NY): Guilford Press; 2001:15-34.

35. Cleeland CS, Ryan KM. Pain assessment: global use of the Brief Pain Inventory. Ann Acad Med Singapore 1994;23:129-38.

36. Watt-Watson J, Stevens B, Katz J, et al. Impact of preoperative education on pain outcomes after coronary artery bypass graft surgery. Pain 2004;109:73-85.

37. Hubbard AE, Ahern J, Fleischer NL, et al. To GEE or not to GEE: comparing population average and mixed models for estimating the associations between neighborhood risk factors and health. Epidemiology 2010;21:467-74.

38. Schug SA, Pogatzki-Zahn EM. Chronic pain after surgery or injury. Pain Clin Updates 2011;19:1-5.

39. Wu CL, Raja SN. Treatment of acute postoperative pain. Lancet 2011;377:2215-25.

Affiliations: Centre de recherche de Centre hospitalier de l'Université de Montréal (Choinière); Département d'anesthésiologie (Choinière, Cogan), Université de Montréal; Montreal Heart Institute Research Centre (Choinière, Carrier, Cogan, Racine, Taillefer), Montréal, Que.; Faculty of Nursing (Watt-Watson, Costello), University of Toronto; Institute for Clinical Evaluative Sciences and Institute of Health Policy, Management and Evaluation (Victor), University of Toronto, Toronto, Ont.; Maritime Heart Center (Baskett), Queen Elizabeth II Health Sciences Centre, and Department of Surgery (Baskett), Dalhousie University, Halifax, NS; Institut universitaire de cardiologie et de pneumologie de Québec, and Département d'anesthésiologie (Bussières), Université Laval, Québec, Que.; Department of Surgery (Carrier), Université de Montréal, Montréal, Que.; Peter Munk Cardiac Centre, University Health Network (Costello, Feindel), Toronto, Ont.; Department of Surgery (Feindel), University of Toronto, Toronto, Ont.; Biostatistics Services, Montreal Health Innovation Coordinating Center (Guertin), Montreal Heart Institute, Montréal, Que.; Lawson Health Research Institute and St. Joseph's Health Care London (Racine), London, Ont.; Pain Clinic (Taillefer), Centre hospitalier de l'Université de Montréal, Montréal, Que.

Contributors: Manon Choinière and Judy Watt-Watson were the principal investigators of the CARD-PAIN project; they designed the study and were responsible for its overall coordination. Funding was obtained by Manon Choinière, Judy Watt-Watson, Michel Carrier, Jennifer Cogan, Judy Costello, Christopher Feindel and Marie-Claude Guertin, all of whom prepared the grant proposal along with MarieChristine Taillefer. Manon Choinière, Michel Carrier, Jennifer Cogan, Marie-Christine Taillefer (Montréal), Judy Watt-Watson, Judy Costello, Christopher Feindel (Toronto), 
Jean Bussières (Québec) and Roger Baskett (Halifax) coordinated the study in their respective sites and supervised the research assistants' work with regard to patient recruitment and data collection. Mélanie Racine and Marie-Christine Taillefer also participated in patient recruitment and data collection in the Montréal site. Marie-Claude Guertin prepared the initial statistical plan and sample size estimation, and her team conducted part of the statistical analyses. Charles Victor proposed and conducted further statistical analyses, which were approved by Marie-Christine Guertin. All of the authors contributed to the interpretation of the results. Manon Choinière, Judy Watt-Watson and Charles Victor contributed to the drafting of the manuscript. All of the authors revised the manuscript critically for important intellectual content and approved the final version submitted for publication.

Funding: The CARD-PAIN study was supported by grants from the Canadian Institutes of Health Research (CIHR grant no. MOP-69065) and the Research Foundation of the Montreal Heart Institute. At the time of the study, Jennifer Cogan was a research scholar of the Fonds de la recherche en santé du Québec, and Mélanie Racine and Marie-Christine Taillefer were CIHR Strategic Training Fellows in Pain: Molecules to Community.

Acknowledgments: The authors thank the research nurse coordinator of the CARD-PAIN study, Mrs. Hélène Lanctôt (Centre de recherche du Centre hospitalier de l'Université de Montréal [CRCHUM]) and all of the research assistants (nurses, respiratory therapists and graduate students) who were involved in patient recruitment and data collection at the study sites. The authors thank the patients who participated in the study, and the surgeons, anesthesiologists and nurses from the study sites, whose collaboration made this project possible. The authors thank Mrs. Marie-Christine Tremblay (Montreal Health Innovation Coordinating Center [MHICC]), who was in charge of all the data management. Mrs. Anna Nozza (MHICC) deserves special thanks for having performed most of the initial statistical analyses. Finally, the authors thank Mrs. Isabelle Jeannotte (CRCHUM) for her technical assistance in the preparation the manuscript. 